\title{
Systemic Importance Index for Financial Institutions: A Principal Component Analysis approach
}

\author{
Carlos León* \\ Andrés Murcia** \\ cleonrin@banrep.gov.co \\ amurcia@minhacienda.gov.co
}

* Financial Infrastructure Oversight Department, Payment Systems and Banking Operation Division (PSBOD), Banco de la República (BR). MSc., HEC - Université de Lausanne. [corresponding author].

** Senior Advisor on Financial Affairs, Department of Macroeconomic Policy. Ministry of Finance and Public Credit. MPhil., Toulouse School of Economics.

Fecha de recepción: 14 de junio de 2013

Fecha de aceptación: 2 de septiembre de 2013

Forma de citar:

Leon, C. \& Murcia, A. (2013). Systemic Importance Index for Financial Institutions:

A Principal Component Analysis Approach. ODEON, 7, 127-167. 



\section{Introduction}

An institution may be considered as systemically important if its failure or malfunction causes widespread distress, either as a direct or indirect impact (i.e. contagion), where the main criterion for assessing systemic importance relates to their potential to have a large negative impact on the financial system and the real economy (IMF et al. ,2009).

Defining whether a financial institution ${ }^{1}$ is systemically important or not may be decidedly intricate but key to the oversight, supervision and regulation of the financial system. To be able to identify systemic importance may serve the purpose of assisting financial authorities in focusing their attention and resources -the intensity of oversight, supervision and regulation- where the systemic severity resulting from a financial institution failing or near-failing is estimated to be the greatest. Identifying systemically important institutions may also serve financial authorities for enhanced policy-making (e.g. prudential regulation, oversight and supervision) and decision-making (e.g. resolving, restructuring or providing emergency liquidity).

Literature has acknowledged the existence of three key criteria for assessing and identifying the systemic importance of financial institutions: size, connectedness and substitutability (IMF et al., 2009; Manning et al., 2009). According to IMF et al. (2009), it is possible to relate size and non-substitutability to the direct impact of an institution failing to fulfill its role within the financial markets, whilst connectedness relates to the indirect impact of such event.

Despite the intuitiveness of these concepts, assessing and identifying systemic important institutions remain a non-trivial task that implies several challenges. Two

1 For this document the authors embrace the term "financial institution" as comprising depository institutions (e.g. banks or savings associations), brokers, dealers, investment companies (e.g. mutual funds), insurance companies, investment advisers and credit unions; this is, those that may not be regarded as a "financial market utility", where the latter is defined as in the 2010 Dodd-Frank Wall Street Reform and Consumer Protection Act: "any person that manages or operates a multilateral system for the purpose of transferring, clearing or settling payments, securities, or other financial transactions among financial institutions or between financial institutions and the person". The 2010 Dodd-Frank Wall Street Reform and Consumer Protection Act (hereafter Dodd-Frank Act) is United States of America's legislative response to the most recent episode of international financial crisis. Its main objective is to promote financial stability of the United States, whereas Section 804 of the Act addresses the main considerations to designate what systemic importance is. 
challenges are particularly demanding. First, designing metrics for connectedness and substitutability may require, as acknowledged by recent literature, non-standard data sources and techniques, such as financial infrastructures' data and network theory, respectively. Second, choosing a methodology capable of robustly aggregating the metrics designed for the three aforementioned concepts into a systemic importance index may be intricate.

A consultative document by the BIS - Basel Committee on Banking Supervision introduced an early approach to both challenges (BCBS-BIS, 2011). Regarding the first challenge, the proposal relies mainly on traditional balance sheet data, against growing agreement on the convenience of using other data sources and technical approaches (Uribe, 2011a,b; León et al., 2011; ЕСв, 2010). About the second challenge, somewhat divergent from IMF et al. (2009) concerns and suggestions, the proposal employs an equal and fixed weighting scheme for aggregating five key indicators (i.e. each one assigned a $20 \%$ weight), where the relevance of each key indicator does not seem to follow any technique-quantitative or qualitative ${ }^{2}$. An equal and fixed weighted scheme does not allow quantifying the relative importance of each different characteristic into the systemic importance of financial institutions.

Unlike the BCBS-BIS (2011) proposal, León and Machado (2013) tackle the first challenge by using balance sheet data and an application of network theory to the large-value payment system's data. They design four inputs or metrics for assessing size, connectedness and substitutability for the Colombian financial system. Size is captured via the volume of deposits and money market borrowing, and the volume of financial assets under management. Connectedness is captured by measuring the contribution of each institution to the number and volume of the large-value payment system's transactions. Substitutability is captured by measuring the betweeness centrality (i.e. the brokerage role) of each institution within the large-value payment system's network of transactions.

Regarding the second challenge, León and Machado (2013) employ Fuzzy Logic, an Engineering-type approach based on the deconstruction of expert knowledge into a method that imitates the way experts themselves think about the decision process regarding what a systemically important financial institution is. Despite

2 Other drawbacks of the BCBS-BIS (2011) methodological proposal are briefly discussed in León and Machado (2013), especially regarding the convenience of considering expert judgment as a key input for deciding the weighting scheme. Other comments to the consultative document are posted in the BIS' webpage (http://www.bis.org/publ/bcbs201/cacomments.htm).

PP. $125-165$ • N. ${ }^{\circ} 7$ / 2012-2013 
its advantages, such as capturing non-linearities in the aggregation of key indicators and incorporating IMF et al. (2009) recommendations about the importance of expert judgment and qualitative inputs, the significance of each input or metric is not tested (i.e. relies on expert knowledge), whilst the weight assigned to each input or metric is non-observable.

In order to overcome some of the drawbacks of both proposals regarding the second challenge (i.e. the aggregation of key indicators), the herein paper implements Principal Components Analysis (PCA) on León and Machado (2013) aforementioned four inputs for size, connectedness and substitutability for the Colombian financial market. Therefore, the purpose of this implementation is twofold: (i) identifying how significant those inputs are for differentiating the relative systemic importance for Colombian financial institutions, and (ii) obtaining an alternative Systemic Importance Index with observable but non-arbitrary weights .

Results confirm that (i) the three concepts and their metrics are explanatory and non-redundant for differentiating financial institutions' relative systemic importance; (ii) connectedness is the single most important input, followed by size and substitutability, in that order; (iii) Commercial Banks are the most systemically important financial institution in the Colombian case; (iv) some local non-banking institutions (i.e. Brokerage Firms), despite being insignificant by the balance sheet exposure they engender, are systemically important because of their role within the local financial system.

The document is structured as follows: based on León and Machado (2013), the next section briefly introduces the systemic importance concept. The second section introduces PCA basics and documents its application to related studies. The third section presents some aggregated results for the Colombian case based on information available from financial institutions participating in the local largevalue payment system (CUD) ${ }^{3}$ as of May, June and July 2011. Based on the aggregated results, the fourth section exhibits the systemic importance assessment for Colombian financial institutions. The fifth section presents some final remarks. An exhibit provides further information about some of the methodological approaches herein implemented for assessing connectedness and substitutability.

\footnotetext{
3 Colombia's large-value payment system (CUD) is a direct participation system where any financial institution can maintain deposits and conduct transactions with other participants without the need for an agent or intermediary. During the three months comprising the analysis (May, June, July 2011) about 147 financial institutions made transactions within the CUD.
} 


\section{Systemic risk and systemic importance ${ }^{4}$}

As presented by IMF et al. (2009), G20 countries embrace the following general definition of systemic risk: the risk of disruption of financial services that (i) is caused by an impairment of all or parts of the financial system and (ii) has the potential to have serious negative consequences for the real economy. Regarding payment systems, the Committee on Payment and Settlement Systems (CPSS-BIs, 2011) define it as the risk that the inability of a financial institution to meet its obligations could result in the inability of other system participants or of financial institutions in other parts of the financial system to meet their obligations as they become due.

Irrespective of which of these definitions is embraced, and despite there is not a single definition of risk that can be completely satisfactory in every situation (Dowd, 2005) $)^{5}$, it is common to think of risk as a function based on two parameters: frequency and severity (Condamin et al., 2006), also referred as likelihood and impact, respectively (Gallati, 2003). Although academic effort has traditionally focused on systemic concerns based on the estimation of systemic risk (i.e. the product of frequency and impact, as in Norman et al. (2009)), there is a recent interest in focusing on systemic severity or importance. ${ }^{6}$

For example, Paul Tucker, Executive Director for Markets and member of the Monetary Policy Committee of the Bank of England, pointed out the following (Tucker, 2005):

[T]he interesting question is not whether or not risk will crystallize, as in one form or another risks crystallize every day. Rather, the important question is whether, in the event of nasty shocks, our capital markets can absorb them or whether they have developed characteristics which may, as some suggest, leave them vulnerable.

$4 \quad$ This section is transcribed from León and Machado (2013).

5 A proper definition of risk is beyond the aim of this paper. Interesting reviews of risk definitions and their implications can be found in Hubbard (2009).

6 Some authors (Rebonato, 2007; Taleb, 2007) argue that models and techniques for estimating very low probabilities of very disastrous occurrences have demonstrated to yield poor results, and even question the usefulness of those models and techniques for capturing extreme adverse events not found in historical data. Rebonato (2007) also questions the convenience of regulators using VaR-type approaches (i.e. based on estimating low probabilities) to determine prudential capital since even a high percentile (e.g. 99\%) would allow a firm to incur losses equal to its regulatory capital rather often (i.e. 2-3 times a year); not to mention if extreme losses cluster, as they do. 
More recently, as a result of the most recent episode of global financial crisis, the consultative report "Principles for Financial Market Infrastructures" published by the Bank of International Settlements' Committee on Payment and Settlement Systems (CPSS-BIS, 2011) includes several principles that aim to provide a high degree of confidence that a financial market infrastructure will continue operating and serve as a source of financial stability even in extreme market conditions. Principles 4 and 7 emphasize the importance of focusing on the severity of the systemic shocks; the latter addresses liquidity risk for financial market infrastructures:

Principle 7 (Liquidity Risk): A financial market infrastructure should maintain sufficient liquid resources to effect same-day and, where appropriate, intraday settlement of payment obligations with a high degree of confidence under a wide range of potential stress scenarios that should include, but not be limited to, the default of [one/two] participant [s] and [its/their] affiliates that would generate the largest aggregate liquidity need in extreme but plausible market conditions.

Such increasing interest in the impact of systemic shocks -beyond the interest in their frequency- results from the intrinsic characteristics of the financial and payments systems. As pointed out by Haldane (2009) and León et al. (2011), financial and payments networks nowadays may be described as robust to random disturbances, but highly susceptible to targeted attacks. ${ }^{7}$ This results from the systemic importance of financial institutions (e.g. size, connectedness, substitutability) being distributed with a high degree of asymmetry (right skew) and excess kurtosis, where the average institution is of low systemic importance (Figure 1, upper panel) and the average default or failure-to-pay results in low systemic severity (Figure 1, lower panel); correspondingly, systemically important institutions and their consequent high systemic severities lurk in the extreme right tail of the distributions.

$7 \quad$ As mentioned by Haldane (2009), this explains why there exist long periods of apparent robustness, where peripheral -not systemically important- nodes are subject to random shocks, and short but severe episodes of systemic distress, where systemically important institutions endanger financial stability. Therefore Haldane's characterization of the current international financial network: "robust-yet-fragile". 
Figure 1. Systemic importance and systemic severity

Systemic
Importance

Systemic

Severity

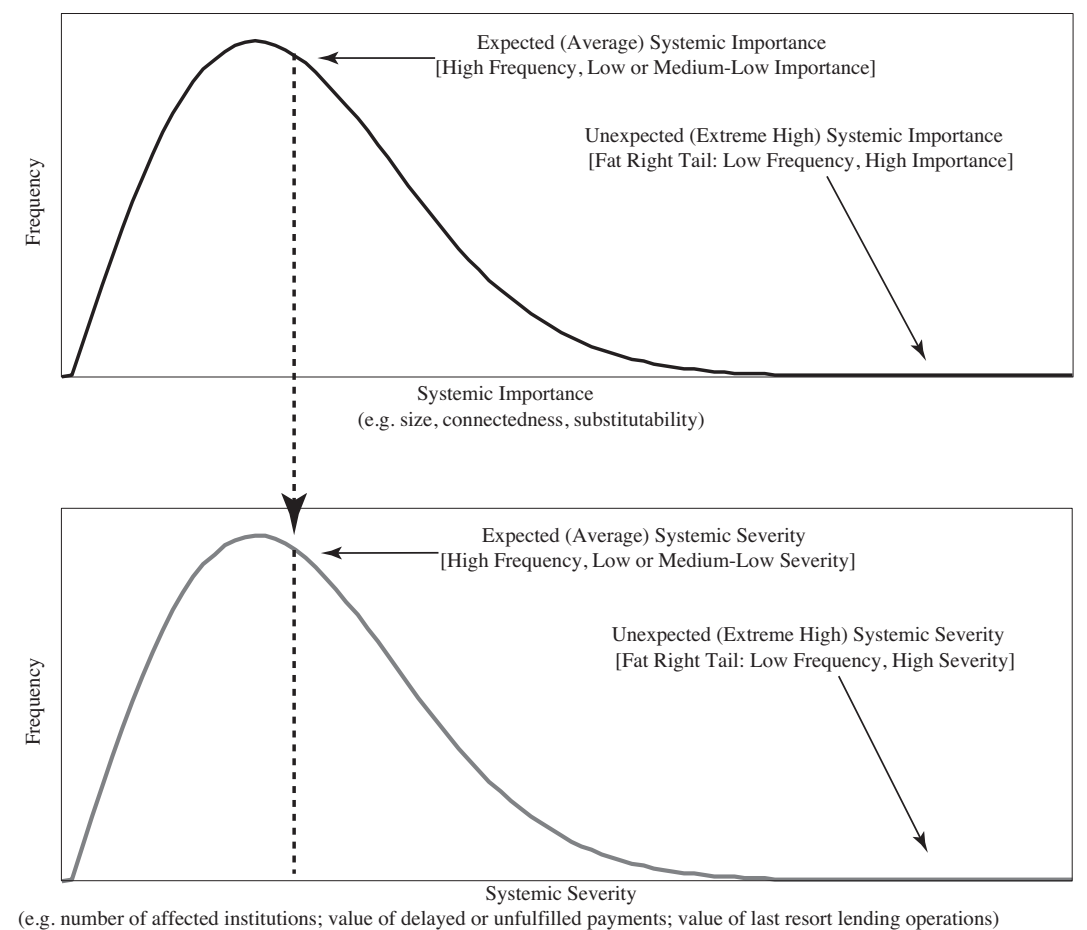

Source: León and Machado (2013).

This means that traditional focus on estimating systemic risk as the sum of multiplying each participant's estimated frequency of failure (or near failure) times its corresponding estimated impact may be dangerously diverting financial authorities from its aim of ever preserving financial stability and payment systems safety: on average the financial stability and payments system's safety may be "guaranteed", but not when confronted with a systemically important participant failing. This is, focusing on estimating probabilities of systemic events happening would mean preparing (i.e. overseeing, supervising, regulating) for a severe systemic shock based on the impact of a single -systemically modestaverage institution.

Moreover, estimating systemic risk as the sum of multiplying each participant's estimated frequency of failure (or near failure) times its corresponding estimated impact assumes that failures or near failures by different participants do not co- 
me together (i.e. they are independent) ${ }^{8}$ As recently exhibited by the concurrent episodes of distress of AIG, Lehman and Bear Sterns, such independence is by no means guaranteed.

Therefore, as financial authorities should be prepared to confront a non-average but extreme threat to financial stability or payment systems' safety, the supervision, oversight and regulation should be designed to cope with one (or even two) systemically important institution(s) failing or near failing, as suggested by CPSS-BIS (2011) when formulating Principles 4 and 7 for measuring, monitoring and managing credit and liquidity risks for financial infrastructures. In this sense, financial authorities' prudential supervision, regulation and oversight (i.e. policy-making) and decision-making rely on defining what systemic importance is, and identifying institutions that comply with such definition.

According to IMF et al. (2009), G-20 members state that an institution may be considered as systemically important if its failure or malfunction causes widespread distress, either as a direct or indirect impact (i.e. contagion), where the main criterion for assessing systemic importance relates to their potential to have a large negative impact on the financial system and the real economy. This overall criterion may be conveniently explained by three more concise criteria: size, connectedness and substitutability (IMF et al., 2009; Manning et al., 2009).

Designing metrics which capture these criteria is complex and pertains to an ongoing debate. The authors' choice of metrics follows recent literature (Uribe, 2011a,b; León et al., 2011; ЕСв, 2010) about the convenience of using new data sources and techniques for measuring size, connectedness and substitutability.

\subsection{Size}

Some authors regard an institution as systemically important when exceeding an asset-size cutoff (Saunders et al., 2009), whilst others (IMF et al., 2009) prefer to gauge the amount of financial services it provides to the system. This is the traditional approach to systemic risk, where the systemic importance of a financial

8 When estimating market risk this inconvenience is absent: it is impossible that two (or more) scenarios crystallize; there is a unique outcome (i.e. if return resulted to be $1.2 \%$ all other realizations are impossible), thus assuming independence of each realization is appropriate. For estimating systemic or credit risk, where simultaneous occurrence of outcomes is feasible (e.g. several firms may enter into default simultaneously or within a short period), this assumption may be inappropriate. 
institution generally increases with its size, where systemically important institutions are labeled as too-big-to-fail.

When considering the amount of financial services provided to the system as the metric for size some intuitive and straightforward key indicators emerge. Because they belong to the traditional institution-centric approach to micro-prudential supervision, standard accounting data already contains relevant information, such as balance and off-balance sheet exposures (e.g. deposits, money market borrowing and lending) and volume of assets it warehouses or manages, etc.. Other relevant size indicators such as the volume of payments by individual institutions are not publicly disclosed, but are available for financial authorities via their involvement in large-value payment systems or via their oversight and supervision duties.

\subsection{Connectedness}

According to the European Central Bank (2010) the properties and behavior of an institution may be affected by institutions that have links to it, and also by other institutions that have no direct links, but are linked to its neighbors. Therefore, the larger the number -and volume- of the links an institution maintains with other market participants, the larger the contagion or spillovers it may generate; this is, the systemic importance of a financial institution generally increases with its degree of connectedness. Despite its intuitiveness this is a rather novel approach to systemic risk, where systemically important institutions are labeled as tooconnected-to-fail (León et al., 2011; Machado et al. 2010; Chan-Lau, 2010; ЕСв, 2010; Clark, 2010; Zhou, 2009).

Unlike financial institutions' size, connectedness may be intricate to assess, with regulators and central banks currently lacking the resources to carry out this kind of analysis (Clark, 2010). Network theory ${ }^{9}$ provides some concepts and metrics that may assist the assessment of connectedness. The most simple concept is the

\footnotetext{
$9 \quad$ Network theory (also referred as network topology or analysis) is a method used in Statistical Physics to understand and analyze the structure and functioning of complex networks. As acknowledged in authors' prior works (León and Machado, 2013; León et al., 2011; Machado et al., 2010), network theory provides appealing methods and techniques to cope with the need to change from an institution-centric to a systemic approach. The studies by Soramäki et al. (2006) and Bech and Garrat (2006) use network theory to characterize the United States (Fedwire) payment system, while Ianoka et al. (2004) apply it to the Japan case (BoJ-Net). Cepeda (2008) applies network theory to the Colombian large-value payment system (CUD) to quantify the impact of failures on its stability.
}

PP. $125-165 \cdot N .{ }^{\circ} 7 / 2012-2013$ 
in-degree and out-degree centrality, which refer to the number of "neighbors" or "partners" an institution has within the network, where the former (latter) corresponds to incoming (outgoing) flows.

Traditional application of network theory for assessing systemic risk relies on balance sheet data such as interbank funding and lending, as in Garrat et al. (2011) or Chan-Lau (2010). Alternatively León and Machado (2013), León et al. (2011) and Machado et al. (2010) use large-value payment system's databases. The choice of connectedness metric and of data source (i.e. balance sheet or large-value payment system) will be addressed in the third section. For more details, see Exhibit A.

\subsection{Substitutability}

If the absence of a financial institution distorts the system because it is difficult (or impossible) to find another institution able to provide the same (or similar) type and volume of financial services (e.g. settlement, payments, interbank lending, custody, brokerage), such institution is systemically important. As pointed out by Manning et al. (2009), the severity of the impact of a payment system failure, and hence the extent of systemic risk, depends critically on whether substitutes are readily available to allow payment flows to be rerouted via another system. Consequently, the systemic importance of a financial institution generally decreases with its degree of substitutability, where connectedness and substitutability are both related to the too-connected-to-fail criteria.

Unlike financial institutions' size, the degree of substitutability may be intricate to assess. Despite there being cases in which it is easy to determine that a participant or infrastructure is non-substitutable (e.g. if there is a sole infrastructure in charge of all the market's clearing), it may be cumbersome to determine other participants' degree of non-substitutability.

For these cases network theory provides some concepts and metrics that may assist the assessment of substitutability. An interesting concept is betweenness centrality (Newman, 2010 and 2003; Buechel and Buskens, 2008; de Nooy et al., 2005), which is a measure of a network's resilience based on the assessment of the involvement of a participant in the indirect connection of all other participants.

As with connectedness, network theory for assessing substitutability could rely on data gathered from institutions' balance sheets (e.g. interbank funding and lending) or from large-value payment systems. The choice of substitutability metric and of data source (i.e. balance sheet or large-value payment system) will be addressed in the third section. 


\section{PCA basics and related applications}

As previously illustrated, the characteristics that literature has identified as key determinants of systemic importance are financial institutions' size, connectedness and substitutability. Nevertheless, two main complications may be faced when calculating a measure associated to systemic importance of financial institutions. The first one consists of obtaining an appropriate measure of each dimension of the problem; this is how to gauge the main characteristics or properties of the system. The second one is related to how to weight these characteristics in order to construct an aggregate indicator, where this indicator may be used as a measure of systemic importance of different financial institutions. Because the first issue has been already addressed when choosing León and Machado (2013) metrics, this section addresses the second complication.

In Economics and many other fields it is quite common to deal with a set of possible correlated variables and observations. The main problem emerges when trying to summarize the common information assigning an appropriate weight for each of the variables.

The case in hand is no exception since we have four characteristics (metrics) related to systemic importance for a set of financial institutions, and the weighting scheme is unknown. Therefore, the main objective is to construct a consolidated measure of systemic importance taking into account the chosen set of characteristics. As illustrated below, this general concern has been present in many fields and sciences, and a common solution has been the use of Principal Components Analysis (pca).

The basic intuition of this methodology consists of summarizing the information contained in a large number of correlated variables into a new set of variables, much smaller than the former one, named the "principal components". Those components represent a linear combination of an uncorrelated set of the characteristics in an ordered manner. The first principal component retains most of the common variation in all the original variables.

Campbell et al. (1997) describe pca as a technique that permits the reduction of the number of variables being analyzed without losing too much information in the covariance matrix. Our objective is to reduce the dimension form of $N$ systemic characteristics of financial institutions into $K$ factors. The principal components serve as these factors. According to this, the first principal component corresponds to the linear combination of these systemic characteristics with maximum variance, and the second principal component represents the linear combination of the PP. $125-165 \cdot N .^{\circ} 7 / 2012-2013$ 
systemic characteristics with maximum variance of all combinations orthogonal to the first principal component.

Using the exposition of this methodology presented in Campbell et al. (1997), the first principal component corresponds to $x_{1}^{* *} R_{t}$ where the vector $x_{1}^{*}$ of size $(N \times 1)$ is the solution to the following problem:

$$
\operatorname{Max}_{\mathrm{x} 1} \mathrm{x}_{1}^{\prime} \Omega \mathrm{x}_{1}
$$

subject to

$$
\mathrm{x}_{1}^{\prime} \mathrm{x}_{1}=1
$$

Where $\Omega$ represents the sample covariance matrix of a set of variables which are denoted by $R_{t}$. The solution to this problem (x) corresponds to the eigenvector associated with the largest eigenvalue of $\Omega$. We denote the scoring factor of each characteristic as its respective position in this eigenvector.

If the linear combination expressed in this eigenvector can explain a representative fraction of the information of the covariance matrix, then it is possible to just use the first principal component in order to assign an appropriate weight to the different variables. As a result we can summarize in an effective way the implicit information of different characteristics and individuals in a linear form.

PCA methodology has been widely applied in many fields. Commonly, the main objective is to construct an aggregate measure combining different characteristics which can be correlated among them. Some PCA-based related applications are listed for illustrative purposes: the construction of an index for the quality of international universities (Steiner, 2006); households' wealth indexes for India (Filmer and Pritchett, 1998); stock market indexes (Feeney and Hester, 1964); an index of credit rating history of loans granted by financial institutions to particulars in Colombia (Murcia, 2007); a composite index to measure economic activity (FRB-Dallas, 2003); a Real Sector Business Confidence Index for Turkey (Ece and Hamsici, 2005); an index to measure financial markets' stress (Amol, 2010); a financial stability index for Colombia (Morales and Estrada, 2010) and financial conditions indexes for different countries (Hatzius et al., 2010; Gómez et al., 2011), among many others.

PCA approach has already been used in the systemic risk literature also. For instance, in order to capture the systemic importance of financial institutions in the United States, Billio et al. (2010) used this approach to capture the interconnectedness among the monthly returns of hedge funds, banks, brokers, and insurance. 
Rodriguez-Moreno and Peña (2011) study and compare different systemic risk measures for the biggest banks in Europe and the Unites States. They find that simple measures based on PCA of banks' credit default swaps (CDS) and interbank rates performed better than more complicated measures based on structural credit risk models (à la Merton, 1974), collateralized debt obligations (CDO) indices and their tranches, multivariate densities and co-risk measures. Additionally, De Cadenas et al. (2010) used PCA in order to identify and evaluate different sources of risk when identifying the systemic nature of an entity. Their analysis shows that all considered institutions contribute to systemic risk, albeit to a different degree, depending on various risk factors such as size, inter-connection, unsubstitutability, balance sheet and risk quality.

Maybe the most important work on systemic risk under PCA approach is Kritzman et al. (2010). Their work studied the statistical properties and association of a big set of financial assets. In this paper they introduced a very useful concept called "absorption ratio" as a measure of financial fragility. This ratio is defined as the proportion of variance which is explained by a finite number of eigenvectors. In the words of the authors: "A high value for the absorption ratio corresponds to a high level of systemic risk, because it implies the sources of risk are more unified. A low absorption ratio indicates less systemic risk, because it implies the sources of risk are more disparate". Kritzman et al. (2010) stress the fact that scenarios with high systemic risk do not necessarily lead to asset depreciation or financial turbulence; it could be simply an indication of market fragility since a shock is more likely to propagate quickly and broadly when sources of risk are tightly coupled.

However, to the knowledge of the authors, this methodology has not been used in order to evaluate the systematic importance for financial institutions in Colombia, nor to a combination of metrics for size, connectedness and substitutability. The basic idea is to combine appropriately the characteristics that the literature has identified as the determinants of systemic importance, and then to construct a PCAbased index using the scoring factors of the first principal component. The value of the index would allow for ranking different financial institutions according to their systemic importance.

\section{PCA model for identifying systemic importance}

Based on the basic concepts introduced in the previous section, and based on the metrics designed by León and Machado (2013) following criteria defined by IMF et 
al. (2009) and Manning et al. (2009), this section introduces the authors' proposal for designing a PCA-based Systemic Importance Index.

\subsection{The inputs}

According to recent literature on systemic importance for financial institutions and payment systems (IMF et al., 2009; Manning et al., 2009), the most relevant criteria are size, connectedness and substitutability, where the first two relate to their potential to have a large negative impact on the financial system and the real economy, whereas the latter relates to the magnitude of the indirect impact.

Consequently, based on León and Machado (2013), the authors define four key indicators that aim to capture size, connectedness and substitutability, as exhibited in Table 1. Concurrent with IMF et al. (2009), the authors embrace the amount of financial services each institution provides to the system as a metric for size, with standard balance sheet data such as (i) volume of deposits and money market borrowing, and (ii) financial assets under management. The first one is intended to capture market exposure to credit institutions while the second captures market exposure to asset management institutions.

Concerning connectedness and substitutability the authors agree with recent literature that calls for network theory $(\mathrm{ECB}, 2010)$ as a way to gain a better understanding of the financial system. However, unlike standard application of network theory, the authors avoid using balance sheet data as the input for such proposal, and decide to use data from the large-value payment system as the primary source of information for assessing both criteria; this is also the choice of various authors for analyzing how financial institutions interact with each other (León and Machado, 2011; Leon et al., 2011; Machado et al., 2010; Cepeda, 2008; Soramäki et al., 2006; Bech and Garrat, 2006; Ianoka et al., 2004).

As suggested by León and Machado (2013) and León et al. (2011), using largevalue payment system data has several advantages for assessing connectedness and substitutability: (i) it is not clear whether off-balance positions are being captured or not when using claims, whilst payments comprise all transactions between payments system's participants; (ii) unlike claims, relying on payments allows for considering liquidity as a key factor in systemic risk; (iii) as emphasized by Kodres (2009), failure or insolvency are not the only sources of systemic shocks, but mere failure-to-pay or non-payment of transactions can gridlock the entire financial system; and (iv) as acknowledged by Tumpel-Gugerell (2009), a particular institution might not only be systemically relevant because other institutions are financially 
exposed to it via balance sheet positions, but also because other market participants rely on the continued provision of its services.

It is important to emphasize that the choice of broad key indicators follows several considerations. First and most important, broad key indicators allow for assessing systemic importance of banking and non-banking financial institutions. Unlike most models on assessing systemic importance, which are focused on banking institutions (as in BCBS-BIS (2011)), the authors consider imperative to be able to consider non-banking institutions as relevant as banking institutions; as non-banking-related systemic events have demonstrated (e.g. LTCM, Lehman, AIG, Bear Sterns, Freddie Mac and Fannie Mae), and as put forward by Ötker-Robe et al. (2011), it is essential to improve the understanding of the shadow banking system to prevent non-banking institutions from gaining systemic importance in an unnoticed manner. ${ }^{10}$

Second, broad key indicators allow for a parsimonious model, which would allow for continuous (e.g. monthly) monitoring of systemic importance. Third, broad key indicators are convenient for comparing results across different financial systems.

Table 1. Systemic importance key indicators

\begin{tabular}{|c|c|c|c|}
\hline Key indicators & Description & $\begin{array}{c}\text { Source / } \\
\text { Estimation }\end{array}$ & $\begin{array}{c}\text { Rationale } \\
\text { (When facing a failing } \\
\text { or near failing institution...) }\end{array}$ \\
\hline $\begin{array}{l}\text { Volume of } \\
\text { deposits and } \\
\text { money market } \\
\text { borrowing }\end{array}$ & $\begin{array}{l}\text { Face value of liabilities } \\
\text { a financial institution } \\
\text { would fail to pay to the } \\
\text { public and to other par- } \\
\text { ticipants of the financial } \\
\text { system in the short run. }\end{array}$ & $\begin{array}{l}\text { Balance sheet data provided by } \\
\text { the Financial Superintendence } \\
\text { of Colombia. }\end{array}$ & $\begin{array}{l}\ldots \text { the larger the deposits and } \\
\text { money market borrowing... } \\
\text { - the larger the potential loss in } \\
\text { confidence of the public. } \\
\text { - the larger the potential impact } \\
\text { on other institutions' liquidity } \\
\text { and solvency. } \\
\text { - the larger the potential mone- } \\
\text { tary impact of central bank's } \\
\text { liquidity supply to affected } \\
\text { financial institutions. }\end{array}$ \\
\hline
\end{tabular}

10 However each key indicator may be broken down into other -more specific- key indicators; as the consultative document by the BCBS-BIS (2011) suggests. Nevertheless, such decomposition may result in an implicit preference for assessing systemic importance of some types of financial institutions (e.g. commercial banks), whilst overlooking others (e.g. brokerage firms, hedge funds). Hence, authors suggest to use wide-ranging key indicators when initially implementing the proposed model, and subsequently increasing their specificity if necessary. 


\begin{tabular}{|c|c|c|c|}
\hline Key indicators & Description & $\begin{array}{c}\text { Source / } \\
\text { Estimation }\end{array}$ & $\begin{array}{c}\text { Rationale } \\
\text { (When facing a failing } \\
\text { or near failing institution...) }\end{array}$ \\
\hline $\begin{array}{l}\text { Volume of } \\
\text { financial } \\
\text { assets under } \\
\text { management }\end{array}$ & $\begin{array}{l}\text { Market value of proprie- } \\
\text { tary assets that may be } \\
\text { sold in order to obtain } \\
\text { liquidity in the short run, } \\
\text { and the volume of assets } \\
\text { from third parties which } \\
\text { could be compromised } \\
\text { or mismanaged in the } \\
\text { short run in case of a } \\
\text { failure or near failure. }\end{array}$ & $\begin{array}{l}\text { Balance sheet data provided by } \\
\text { the Financial Superintendence } \\
\text { of Colombia. }\end{array}$ & $\begin{array}{l}\text {.. the larger the volume of } \\
\text { financial assets under mana- } \\
\text { gement... } \\
\text { - the larger the potential impact } \\
\text { on liquidity and solvency of } \\
\text { other financial institutions via } \\
\text { "liquidity spirals".* } \\
\text { - the larger the potential im- } \\
\text { pact on the real economy via } \\
\text { market prices and portfolios' } \\
\text { mismanagement. } \\
\text { - the larger the potential mone- } \\
\text { tary impact of central bank's } \\
\text { liquidity supply to affected } \\
\text { financial institutions. }\end{array}$ \\
\hline $\begin{array}{c}\text { Contribution } \\
\text { to the payment } \\
\text { system }\end{array}$ & $\begin{array}{l}\text { Contribution to the total } \\
\text { payments of the large- } \\
\text { value payment system, } \\
\text { weighted by the contri- } \\
\text { bution to the total con- } \\
\text { nections of the large- } \\
\text { value payment system } \\
\text { (CUD). }\end{array}$ & $\begin{array}{l}\text { Large-value payments system } \\
\text { statistics provided by Banco de } \\
\text { la República (CUD). }\end{array}$ & $\begin{array}{l}\ldots \text { the larger the volume of } \\
\text { payments and the number of } \\
\text { connections... } \\
\text { - the larger the number of po- } \\
\text { tential institutions affected } \\
\text { and the severity of the affec- } \\
\text { tedness. } \\
\text { - the larger the potential dis- } \\
\text { ruption in the money, capital } \\
\text { and exchange markets. } \\
\text { - the larger the potential mone- } \\
\text { tary impact of central bank's } \\
\text { liquidity supply to affected } \\
\text { financial institutions. }\end{array}$ \\
\hline $\begin{array}{c}\text { Betweenness } \\
\text { centrality }\end{array}$ & $\begin{array}{l}\text { Degree of involvement } \\
\text { of a participant in the } \\
\text {-indirect- connection } \\
\text { of all other participants } \\
\text { within the large-value } \\
\text { payment system (CUD). }\end{array}$ & $\begin{array}{l}\text { Estimated as the change in the } \\
\text { average number of links neces- } \\
\text { sary for each participant to be } \\
\text { connected to all other partici- } \\
\text { pants; if removing an institution } \\
\text { results in a major (minor or nil) } \\
\text { increase in the average number } \\
\text { of links all institutions require to } \\
\text { remain connected as before, the } \\
\text { removed institution is to be con- } \\
\text { sidered as of low (high) substitu- } \\
\text { tability. }{ }^{* *} \text { Data provided by cuD. }\end{array}$ & $\begin{array}{l}\text {... the larger the betweenness } \\
\text { centrality... } \\
\text { - the higher the potential effi- } \\
\text { ciency and safety losses for } \\
\text { the system. } \\
\text { - the larger the potential dis- } \\
\text { ruption in the money, capital } \\
\text { and exchange markets. }\end{array}$ \\
\hline
\end{tabular}

Source: León and Machado (2013)

" "Liquidity spirals" refers to the internal amplifying process whereby a falling asset leads to more sales (deleveraging), which further drives down asset prices, financial intermediaries' profit and loss statements, and balance sheets' net worth (Brunnermeier et al. 2009).

** Refer to Exhibit A for a brief introduction to the measurement of connectedness and betweenness centrality. 
Under the size, substitutability and connectedness criteria proposed by IMF et al. (2009) and Manning et al. (2009), the authors consider size is to be captured directly by key indicators $[\mathrm{A}]$ and $[\mathrm{B}]$, and indirectly by $[\mathrm{C}]$; connectedness is to be captured directly by $[\mathrm{C}]$, and indirectly by [D]; and substitutability is to be captured directly by key indicator [D], and indirectly by [C] (Table 2).

Table 2. How the selected key indicators

of systemic importance relate to criteria

from imf et al. (2009) and Manning et al. (2009)

\begin{tabular}{|l|l|l|l|}
\hline \multirow{2}{*}{\multicolumn{1}{|c|}{ Key indicators }} & \multicolumn{3}{c|}{ Criteria to be captured } \\
\cline { 2 - 4 } & \multicolumn{1}{|c|}{ Size } & Connectedness & Substitutability \\
\hline $\begin{array}{l}\text { [A] Volume of deposits } \\
\text { and money market } \\
\text { borrowing }\end{array}$ & & \\
\hline $\begin{array}{l}\text { [B] Volume of financial } \\
\text { assets under management }\end{array}$ & & & \\
\hline $\begin{array}{l}\text { [C] Contribution to the } \\
\text { payment system }\end{array}$ & & & \\
\hline [D] Betweenness centrality & & & \\
\hline
\end{tabular}

\begin{tabular}{|l|l|}
\hline Directly captured & \\
\hline Indirectly captured & \\
\hline Non-captured & \\
\hline
\end{tabular}

Source: León and Machado (2013).

Moreover, as presented in Table 3, the four systemic importance key indicators concur with the 2010 Dodd-Frank Wall Street Reform and Consumer Protection Act. 
Table 3. How the selected key indicators of systemic importance relate to criteria from the 2010 Dodd-Frank Wall Street Reform and Consumer Protection Act.

\begin{tabular}{|c|c|c|c|c|}
\hline \multirow[b]{2}{*}{ Key indicators } & \multicolumn{4}{|c|}{ Criteria to be captured } \\
\hline & $\begin{array}{c}\text { Aggregate } \\
\text { monetary value of } \\
\text { transactions }\end{array}$ & $\begin{array}{l}\text { Aggregate exposure } \\
\text { to counterparties }\end{array}$ & $\begin{array}{l}\text { Interdependencies } \\
\text { and interactions } \\
\text { with other } \\
\text { participants }\end{array}$ & $\begin{array}{c}\text { Effect on } \\
\text { critical markets, } \\
\text { institutions and the } \\
\text { system }\end{array}$ \\
\hline $\begin{array}{l}{[\mathrm{A}] \text { Volume of deposits }} \\
\text { and money market } \\
\text { borrowing }\end{array}$ & & & & \\
\hline $\begin{array}{l}\text { [B] Volume of } \\
\text { financial assets under } \\
\text { management }\end{array}$ & & & & \\
\hline $\begin{array}{l}{[\mathrm{C}] \text { Contribution to the }} \\
\text { payment system }\end{array}$ & & & & \\
\hline $\begin{array}{l}\text { [D] Betweenness } \\
\text { centrality }\end{array}$ & & & & \\
\hline
\end{tabular}

\begin{tabular}{|l|l|}
\hline Directly captured & \\
\hline Indirectly captured & \\
\hline Non-captured & \\
\hline
\end{tabular}

Source: León and Machado (2013).

The Dodd-Frank Act considers that a financial market utility or payment, clearing or settlement activity may be labeled as systemically important under the following four considerations ${ }^{11}$ : (i) the aggregate monetary value of its transactions, which is to be directly captured by key indicator [C], and indirectly by [A] and [B]; (ii) its aggregate exposure of their counterparties, which is to be directly captured by key indicator [A], and indirectly by [C]; (iii) its relationship, interdependences, or other interactions with other participants, which is to be directly captured by key indicators [D] and [C], and indirectly by [A]; (iv) the effect that its failure or its disruption would have on critical markets, financial institutions, or the broader

11 The Dodd-Frank Act does not limit the considerations to these four; the Act includes a fifth, which states that any other factors may be included because of their relevance. 
financial system, which is to be directly captured mainly by $[A],[B]$ and $[C]$, and indirectly by [D].

\subsection{Testing the inputs' relevance for identifying systemic importance}

The proposed model consists of evaluating the relative characteristics of each financial institution within the Colombian financial system, where the key inputs consist of the four key indicators previously presented (A, B, C, D).

Let A, B, C, D be the systemic importance key indicators as defined and described in Table $1 ; f_{x}^{y}$ the PCA's scoring factor or coefficients of the first principal component for key indicator $x$, for month $y$; and $\lambda^{y}$ the fraction of the total variance of the $y$-month panel that is explained by using the first component of the chosen key indicators. The main results are the following: ${ }^{12}$

Table 4. Scoring factors (May, June, July, 2011)

\begin{tabular}{|c|c|c|c|c|}
\hline $\boldsymbol{f}_{\boldsymbol{x}}$ & $\boldsymbol{y}=$ May & $\boldsymbol{y}=$ June & $\boldsymbol{y}=$ July & Mean \\
\hline $\boldsymbol{x}=\boldsymbol{A}$ & 0.561 & 0.521 & 0.647 & 0.576 \\
\hline $\boldsymbol{x}=\boldsymbol{B}$ & 0.173 & 0.150 & 0.233 & 0.185 \\
\hline $\boldsymbol{x}=\boldsymbol{C}$ & 0.767 & 0.625 & 0.717 & 0.703 \\
\hline $\boldsymbol{x}=\boldsymbol{D}$ & 0.259 & 0.561 & 0.114 & 0.311 \\
\hline$\lambda^{y}$ & $59.2 \%$ & $56.5 \%$ & $50.2 \%$ & $55.3 \%$ \\
\hline
\end{tabular}

Source: authors' calculations.

According to the results, (i) all the scoring factors pertaining to the first component of the model are different from zero; (ii) the scoring factors pertaining to the first component are able to explain more than $50 \%$ of the variance of the key indicators; (iii) on average the contribution to the payment system [C] (i.e. connectedness) is the most important key indicator, followed by the volume of deposits and money market borrowing [A], the betweenness centrality [D] and the volume of financial assets under [B].

In addition, one important fact is that the fraction of the total variance of the $y$-month panel that is explained by using the chosen key indicators is decreasing

12 The four attainable components are presented and briefly discussed in Exhibit B.

PP. $125-165 \cdot N .{ }^{\circ} 7 / 2012-2013$ 
in these months suggesting a decreasing component of aggregate systemic risk. Using the notion of "absorption ratio" proposed by Kritzman et al. (2010), when this proportion is decreasing, it could be an indication of decreasing market fragility since the sources of systemic risk considered were less coupled ${ }^{13}$. It is important to remember that a financial or macro shock is more likely to propagate quickly and broadly when the sources of systemic risk are highly correlated.

If the first component's scoring factors are squared $\left(f_{x}^{y}\right)^{2}$ and since by definition the sum of squared score factors must be equal to one, the results may be interpreted as each key indicator's explanatory share or weight. Table 5 exhibits $w_{x}^{y}$, which corresponds to the weight of key indicator $x$, for month $y$.

Table 5. Key indicators' weights (May, June, July, 2011)

\begin{tabular}{|c|c|c|c|c|}
\hline $\boldsymbol{w}_{\boldsymbol{x}}^{\boldsymbol{y}}=\left(\boldsymbol{f}_{\boldsymbol{x}}^{\boldsymbol{y}}\right)$ & $\boldsymbol{y}=$ May & $\boldsymbol{y}=$ June & $\boldsymbol{y}=$ July & Mean \\
\hline $\boldsymbol{x}=\boldsymbol{A}$ & 0.315 & 0.280 & 0.378 & 0.332 \\
\hline $\boldsymbol{x}=\boldsymbol{B}$ & 0.029 & 0.081 & 0.136 & 0.034 \\
\hline $\boldsymbol{x}=\boldsymbol{C}$ & 0.588 & 0.337 & 0.419 & 0.494 \\
\hline $\boldsymbol{x}=\boldsymbol{D}$ & 0.068 & 0.302 & 0.067 & 0.097 \\
\hline
\end{tabular}

Source: authors' calculations.

As before, for the three months analyzed, the most important key indicator is the contribution to the payment system [C] (i.e. connectedness), which on average explains by itself around $25 \%$ of the variance of the key indicators, followed by the volume of deposits and money market borrowing [A]. In this sense, the results confirm the importance of the too-connected-to-fail criteria as the main determinant of relative systemic importance within the Colombian financial system (as in León and Machado, 2011), where institution's size is also an important determinant, but secondary to connectedness.

13 From a statistical perspective, the main logic of Kritzman (2010) is based on the fact that in the presence of a coupled behavior among variables, it is natural to observe that a large proportion of the variance can be explained with a linear combination of these variables (i.e first principal component). In the case of the presence of uncoupled movements, a bigger number of orthogonal linear combinations should be needed to explain the same proportion of the variance. 


\section{Systemic importance assessment ${ }^{14}$}

Based on the PCA approach to obtaining an index, this section uses May, June and July 2011 data to calculate the individual systemic importance of the financial institutions participating in Colombia's large-value payment system (CUD). During these three months the average of financial institutions directly participating in the CuD was 147, classified as in Table $6 .{ }^{15}$

Each financial institution's systemic importance key indicator was estimated according to Table 1. Indicators [A], [B] were obtained from statistical data from the Banking Superintendence of Colombia. [C] and [D] were obtained based on large-value payment system's databases (Banco de la República-CUD), and calculated as described in Exhibit A.

Table 6. Main Colombian market's financial institutions directly participating in cud (as of May 2011) ${ }^{\mathrm{d}}$

\begin{tabular}{|c|c|c|}
\hline Class & Institution type & Main purpose ${ }^{\mathrm{c}}$ \\
\hline \multirow{3}{*}{$\begin{array}{l}\text { Credit } \\
\text { Institutions } \\
(\mathrm{CI})^{\mathrm{a}}\end{array}$} & Commercial Bank (св) & Provision of deposit and loans, including mortgages. [21] \\
\hline & $\begin{array}{l}\text { Commercial Financial } \\
\text { Corporation (CFC) }\end{array}$ & $\begin{array}{l}\text { Provision of deposit and loans focused on goods and services commercial- } \\
\text { ization (e.g. leasing). [20] }\end{array}$ \\
\hline & Financial Corporation (CF) & $\begin{array}{l}\text { Provision of deposit and loans focused on medium term industrial financ- } \\
\text { ing; akin to an investment bank. [3] }\end{array}$ \\
\hline \multirow{4}{*}{$\begin{array}{l}\text { Non-Credit } \\
\text { Institutitons } \\
(\mathrm{NCI})\end{array}$} & Mutual Fund (MF) & $\begin{array}{l}\text { Provision of investment vehicles with the purpose of investing in securities } \\
\text { and other assets according to the risk profile of the investor. [27] }\end{array}$ \\
\hline & Brokerage Firm (BF) & $\begin{array}{l}\text { Provision of brokerage services with the purpose of buying and selling securi- } \\
\text { ties (e.g. stocks, bonds, currencies); allowed to trade for its own account. [26] }\end{array}$ \\
\hline & Pension Fund Manager (PFM) & $\begin{array}{l}\text { Provision of investment vehicles with the purpose of investing for retire- } \\
\text { ment. [6] }\end{array}$ \\
\hline & Other $^{b}$ & Insurance companies, financial cooperatives and other. [18] \\
\hline
\end{tabular}

${ }^{\text {a }}$ Financial cooperatives pertain to Credit Institutions; due to their low contribution to the cuD and their size they were included in the "Other" class; CIs are the only institutions able to receive last-resort lending liquidity.

b The "Other" class gathers financial institutions characterized by their particularly low (or nil) relevance for the key systemic importance indicators.

${ }^{c}$ Only the main differencing feature appears; the number of institutions as of May 2011 appears in brackets.

${ }^{\mathrm{d}}$ Financial infrastructures and official financial institutions are excluded from this Table and were not analyzed.

Source: León et al. (2011).

14 Results are illustrative. They may not be used to infer credit quality or to make any type of assessment for any financial institution. Results do not represent an opinion or statement of Banco de la República nor of its Board of Directors. The name of each institution is not revealed due to disclosure restrictions.

15 For a brief introduction to the functioning and characteristics of the Colombian large-value payments system (CUD), refer to Banco de la República (2011), León et al. (2011), Machado et al. (2010) or Cepeda (2008). 
Following the methodology for constructing indexes in the literature under PCA approach, let $f_{x}^{y}$ be the coefficient from the first principal component of variance covariance matrix of systemic characteristics for key indicator $x$, for month $y$ (as in Table 4), the Systemic Importance Indicator for a $\alpha$-financial institution $\left(S I I_{\alpha}^{y}\right)$ will be calculated as the standardized value (i.e. in a 0 to 10 scale) of the expression (3)

$$
S I I_{\alpha}^{y}=f_{A}^{y} \times A_{\alpha}+f_{B}^{y} \times B_{\alpha}+f_{C}^{y} \times C_{\alpha}+f_{D}^{y} \times D_{\alpha}
$$

It is worth emphasizing that the Index provides a relative assessment of each institution's systemic importance ${ }^{16}$. Therefore, an Index equal to zero does not correspond to the -absolute- absence of systemic importance for that institution, but a negligible importance with respect to the most important institution.

Table 7 exhibits the top-ten Systemic Importance Indicator for the three chosen periods; due to disclosure restrictions the name of the institution is replaced by its type according to Table 6 , and a distinctive number.

Regarding these results, three comments are worth making. First, the types which concentrate most systemic importance in the Colombian financial market are commercial banks (CBs) and brokerage firms (BFs), as in León and Machado (2013), León et al. (2011) and Machado et al. (2010). Second, the indexes comprise twelve financial institutions, where eight appear every month, two appear in two months, and two appear in just one of them. Third, a single participant (CB1) resulted as the most systemically important financial institution every month, with $\mathrm{CB} 1, \mathrm{CB} 2, \mathrm{CB} 3, \mathrm{CB} 5$ ranking in the top-five every month.

\footnotetext{
16 The proposed measure is relative in terms of a comparison for a group of financial institutions for each observation in time. The score of 10 for each observation is obtained by the most important systemic institution.
} 
Table 7

Systemic Importance Index

(Top-ten financial institutions)

\begin{tabular}{|c|c|c|c|c|c|c|c|c|}
\hline \multirow{2}{*}{ Rank } & \multicolumn{2}{|c|}{ May } & \multicolumn{2}{|c|}{ June } & \multicolumn{2}{|c|}{ July } & \multicolumn{2}{|c|}{ Mean } \\
\hline & Institution & Index & Institution & Index & Institution & Index & Institution & Index \\
\hline 1 & CB1* & 10,0 & $\mathrm{CB} 1 *$ & 10,0 & CB1* & 10,0 & $C B 1^{*}$ & 10,0 \\
\hline 2 & $\mathrm{CB} 2 *$ & 8,1 & CB4* & 9,2 & CB4* & 8,5 & $C B 4^{*}$ & 8,5 \\
\hline 3 & CB3* & 8,0 & CB9 & 7,8 & CB2* & 8,5 & $C B 2 *$ & 8,1 \\
\hline 4 & CB4* & 7,9 & CB2* & 7,7 & CB3* & 8,0 & $C B 3^{*}$ & 7,8 \\
\hline 5 & $\mathrm{BF} 1 *$ & 7,7 & CB3* & 7,5 & CB5* & 6,9 & $B F 1 *$ & 6,9 \\
\hline 6 & $\mathrm{BF} 2 *$ & 7,5 & CB10 & 6,8 & $\mathrm{BF} 1^{*}$ & 6,8 & $B F 2 *$ & 6,9 \\
\hline 7 & CB5* & 6,6 & $\mathrm{BF} 2 *$ & 6,6 & $\mathrm{BF} 2 *$ & 6,6 & $C B 5^{*}$ & 6,6 \\
\hline 8 & CB6* & 6,1 & $\mathrm{BF} 1 *$ & 6,3 & CB8 & 6,5 & $C B 9$ & 6,3 \\
\hline 9 & CB7 & 6,0 & CB5* & 6,3 & CB6* & 6,5 & $C B 6^{*}$ & 6,1 \\
\hline 10 & CB8 & 5,8 & CB6* & 5,6 & CB9 & 6,2 & CB8 & 5,8 \\
\hline
\end{tabular}

(*) Institutions appearing in the three months analyzed.

Source: authors' calculations.

Because the key indicators' data are the same as in León and Machado (2013), CBs emerge as particularly important due to their volume of deposits and money market borrowing, along with their contribution to the large-value payment system (CUD). The two brokerage firms (BFs) appearing in the top-ten rank convey systemic importance because of their particularly high contribution to the largevalue payment system.

It is also important to highlight that network theory based on payment system data allowed the identification of those two BFs as systemically important due to their connectedness. This is not the result of financial system's balance sheet being exposed to BFs, but the result of the financial system relying on these BFs' continuous provision of their services; those two BFs' systemic importance would have been missed using network theory based on traditional balance sheet data.

Concurrent with León and Machado (2013), an important attribute of the Systemic Importance Index is its high level of skewness (Figure 2). Such skewness confirms the intuition regarding the high degree of asymmetry (right skew) of systemic importance, where the average institution is of low systemic importance and the average default or failure-to-pay results in low systemic severity; thus, 
relying on the systemic importance of the average financial institution would divert financial authorities from its aim of ever preserving financial stability and payment systems safety.

Figure 2. Distribution of the Systemic Importance Index
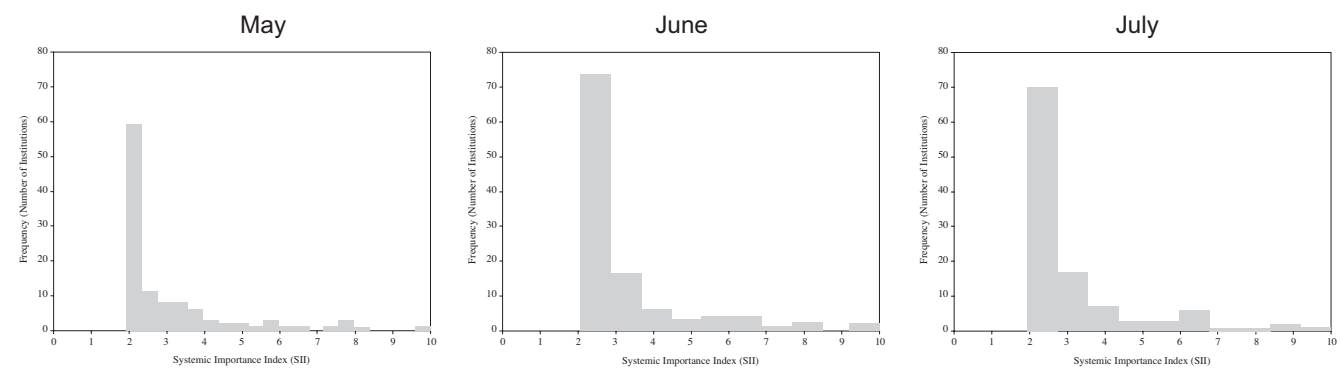

Source: authors' calculations.

\section{Final remarks}

The most recent episode of global market turmoil exposed the limitations resulting from institution-centric metrics and the -resulting- traditional focus on too-bigto-fail institutions within an increasingly systemic-crisis-prone financial system. This has encouraged the appearance of the too-connected-to-fail concept, and has resulted in the emergence of several challenges regarding the estimation of financial institutions' systemic importance by financial authorities.

As previously documented, the main challenges relate to (i) designing measures corresponding to size, substitutability and connectedness, and (ii) choosing a methodology capable of robustly aggregating the metrics designed for the three aforementioned concepts.

Despite the intricacy of the first challenge, there are data sources and methodologies that may overcome some of the difficulties. Vis-à-vis data sources, unlike traditional balance sheet data, financial infrastructure data are particularly dynamic and granular and may help to identify the type, volume and risk profile of the activities and services provided by each type of institution, even at the firm level (Uribe, 2011b). Concerning methodologies, network theory has emerged as an interesting and comprehensive approach to effectively assess financial institutions' connectedness and substitutability, as suggested by Есв (2010) and Uribe $(2011 \mathrm{a}, \mathrm{b})$. Together, financial infrastructures' data (i.e. large-value payment systems) and network theory, are supported by literature (Leon et al., 2011; Machado 
et al., 2010; Cepeda, 2008; Soramäki et al., 2006; Bech and Garrat, 2006; Ianoka et al., 2004) as a convenient approach to better approximate the way financial institutions interact with each other.

Regarding the second challenge, the choice of an aggregating method for the metrics capturing size, connectedness and substitutability is an ongoing topic. Each proposal has its own advantages and disadvantages, and each provides a valuable input for financial authorities.

In the case in hand, because of consisting of a different -purely quantitative- approach, the results from this paper serve the purpose of accompanying the -quantitative and qualitative- outcome of León and Machado (2013). Both methodologies should be regarded as complementary, and their outcomes should not be regarded as substitutes for sound judgment by financial authorities, or the only metrics to use when deciding the systemic importance of a financial institution.

Akin to León and Machado (2013) results based on expert knowledge, results obtained by the PCA-based proposed methodology are straightforward and grant financial authorities with the ability to acquire a comprehensive relative assessment of each financial institution's systemic importance. Both approaches share the advantages of providing a parsimonious and straightforward cardinal classification of financial institutions, which would allow for convenient continuous (e.g. monthly) monitoring of systemic importance, and for the ability to capture the dynamics of the financial market.

Unlike León and Machado, the PCA-based approach is able to (i) quantitatively test the significance of each metric for differentiating systemic importance within financial institutions, (ii) provide observable weights for the index, and (iii) estimate useful statistics such as the absorption ratio proposed by Kritzman et al. (2010) as a proxy of aggregate systemic risk. Unfortunately, this advantage comes at non-trivial costs: (i) the impossibility of capturing non-linearities in the aggregation of key indicators ${ }^{17}$ and (ii) ignoring IMF et al. (2009) recommendations about the importance of expert judgment and qualitative inputs. This reinforces the authors' belief regarding the convenience of developing different approaches with a complementary view.

17 As aforementioned, each principal component corresponds to a linear combination of the inputs or metrics. Thus, non-linear effects arising from progressively concentrating systemic importance factors within a single institution (akin to an anti-diversification effect, as described in León and Machado (2013)) may not be captured by this PCA-based proposal. 
About the results, despite the difference between both aggregation approaches, the purely quantitative PCA-based Systemic Importance Index supports or confirms León and Machado (2013) main findings with their quantitative and qualitative Fuzzy Logic-based Systemic Importance Index. For instance, (i) the three concepts and their metrics are explanatory and non-redundant for differentiating financial institutions' relative systemic importance; (ii) connectedness is the single most important input, followed by size and substitutability, in that order; (iii) Commercial Banks are the most systemically important financial institution in the Colombian case; (iv) some local non-banking institutions (i.e Brokerage Firms), despite being insignificant by the balance sheet exposure they engender, are systemically important because of their role within the local financial system.

Regarding the usage of the PCA-based Systemic Importance Index, financial authorities are to decide whether an important/unimportant threshold is to be defined within the index. Although the authors consider that defining such threshold is intricate and outside the scope of this document, they suggest considering (i) the purpose of defining the threshold (e.g. for defining a capital charge or deciding which institutions to follow closely); (ii) the degree of clustering of the Index (i.e. its skewness); and (iii) a detailed knowledge of the functioning of the financial system.

\section{References $^{18}$}

Amol, A. (2010). "St Louis Fed's Financial Stress Index”, Federal Reserve Bank of St Louis, Appendix, January.

Banco de la República (BR). (2011). Reporte de Sistemas de Pago - 2011, Banco de la República, June.

Basel Committee on Banking Supervision (BCBS-BIS). (2011). Global systemically important banks: assessment methodology and the additional loss absorbency requirement - Consultative Report, Bank for International Settlements, July.

Bech, M. and Garrat, R. (2006). "Illiquidity in the interbank payment system following Wide-Scale Disruptions", Federal Reserve Bank of New York Staff Report, n. ${ }^{\circ} 239$, March.

\footnotetext{
18 Some preliminary versions of published documents $\left(^{\mathrm{a}}\right)$ are available online: [http://www. banrep.gov.co/economic_reports/er_draf.htm].
} 
Billio, M.; Getmansky, M.; Lo, A.; Pelizzon, L. (2010).“Econometric measures of systemic risk in the finance and insurance sectors", NBER Working Paper, n. ${ }^{\circ} 16223$.

Brunnermeier, M.; Crocket, A.; Goodhart, C.; Persaud, A.D.; Shin, H. (2009). The Fundamental Principles of Financial Regulation, International Center for Monetary and Banking Studies, Centre for Economic Policy Research (CEPR), January.

Buechel, B. and Buskens, V. (2008). "The Dynamics of Closeness and Betweenness", Institute of Mathematical Economics Working Papers, n. 398, Bielefeld University.

Campbell, J.; Lo, A.; Mackinlay, A.C. (1997). The Econometrics of Financial Markets, Princeton University Press.

Cepeda, F. (2008). "La topología de redes como herramienta de seguimiento en el Sistema de Pagos de Alto Valor en Colombia”, Borradores de Economía, n. . 513, Banco de la República.

Chan-Lau, J. (2010). "Balance Sheet Network Analysis of Too-connected-to-fail Risk in Global and Domestic Banking Systems”, IMF Working Paper, WP/10/107, International Monetary Fund, April.

Clark, J. (2010). “Too-networked-to-fail”, Risk<online>, June 7th.

Committee on Payment and Settlement Systems (CPSS-BIS).(2011). Principles for Financial Market Infrastructures - Consultative Report, Bank for International Settlements, March.

Condamin, L.; Louisot, J-P.; Naim, P., Risk. (2006). Quantification: Management, Diagnosis and Hedging, John Wiley \& Sons.

De Cadenas, G.; de Mesa, L.; Sanchis,A. (2010). "Systemic Risk, an Empirical Approach”, Banco Santander - Fundación de Estudios de Economía Aplicada, Colección de Estudios, n. ${ }^{\circ} 17$.

De Nooy, W.; Mrvar, A.; Batagelj, V. (2005). Exploratory Social Network Analysis with Pajek, Cambridge University Press.

Dowd, K. (2005). Measuring Market Risk, John Wiley \& Sons.

European Central Bank (ECB). (2010). Financial Stability Review, June.

PP. $125-165$ • N. ${ }^{\circ} 7 / 2012-2013$ 
Federal Reserve Bank of Dallas. (2003). “Composite Index: A New Measure of El Paso's Economy”, Federal Reserve Bank of Dallas - El Paso Branch, Issue 1.

Feeney, G. \& Hester, D. (1964). “Stock Market Indices: A Principal Components Analysis”, Cowles Foundation's Discussion Papers 175, Cowles Foundation, Yale University.

Filmer, D.; Pritchett, L. (1998). "Estimating wealth effects without income or expenditure data-or tears: Educational enrollment in India", World Bank Policy Research Working Paper No, 1994, Development Economics Research Group (DECRG), The World Bank.

Gallati, R. (2003). Risk Management and Capital Adequacy, McGraw-Hill.

Garrat, R.; Mahadeva, L.; Svirydzenka, K. (2011). "Mapping systemic risk in the international banking network", Working Paper, n. ${ }^{\circ}$ 413, Bank of England, March.

Gómez, E.; Murcia, A.; Zamudio, N. (2011). “Financial Conditions Index: A Leading and Early Warning Indicator for Colombia”, Ensayos sobre Política Económica, vol 29. Num. 66, Banco de la República, December.

Haldane,A.G. (2009). "Rethinking the financial network", Speech delivered at the Financial Student Association (Amsterdam, Netherlands), April.

Hatzius, J.; Hooper, P.; Mishkin, F.S.; Schoenholtz, K.L.; Watson, M.W. (2010). "Financial Conditions Indexes: A Fresh Look After the Financial Crisis", National Bureau of Economic Research, Working Paper 16150, July.

Hubbard, D.W. (2009). The Failure of Risk Management, John Wiley \& Sons.

Ianoka, H.; Ninomiya, T.; Taniguchi, K.; Shimizu, T.; Takayasu, H. (2004). "Fractal network derived from banking transaction - An analysis of network structures formed by financial institutions-“", Bank of Japan Working Paper Series, n. ${ }^{\circ}$ 04-E-04, April.

International Monetary Fund (IMF); Bank for International Settlements (BIS); Financial Stability Board (FSB). (2009). "Guidance to Assess the Systemic Importance of Financial Institutions, Markets and Instruments: Initial Considerations”, October.

Kodres, L. (2009). “The Road to Re-Regulation: Repainting the Center Line and Erecting more Guardrails", The World Bank and Banco de España International Conference: 
“Reforming Financial Regulation and Supervision: Going Back to Basics”, Madrid, June 15 .

Kritzman, M.; Li, Y; Page, S.; Rigobon, R. (2010). "Principal Components as a Measure of Systemic Risk", MIT Sloan School Working Paper 4785-10, MIT Sloan School of Management, June 28.

León, C. and Machado, C. (2013). "Designing an expert knowledge-based systemic importance index for financial institutions", Journal of Financial Market Infrastructure, n. ${ }^{\mathrm{o}} 1$, vol. 2 .

León, C.; Machado, C.; Cepeda, F.; Sarmiento, M. (2011). “Too-connected-to-fail Institutions and Payments System's Stability: Assessing Challenges for Financial Authorities", Borradores de Economía, n. . 644, Banco de la República.

Machado, C.; León, C.; Sarmiento, M.; Cepeda, F.; Chipatecua, O.; Cely, Jorge. (2010). "Riesgo Sistémico y Estabilidad del Sistema de Pagos de Alto Valor en Colombia: Análisis bajo Topología de Redes y Simulación de Pagos", Borradores de Economía, n. ${ }^{\circ}$ 627, Banco de la República.

Manning, M.; Nier, E.; Schanz, J. (2009). The economics of large-value payments and settlement: Theory and policy issues for central banks, Oxford University Press.

Merton, R. (1974 ). “On the Pricing of Corporate Debt: the Risk Structure of Interest Rates", Journal of Finance, n. ${ }^{\circ} 29$.

Morales, M. and Estrada, D. (1974). “A Financial Stability Index for Colombia”, Annals of Finance, 6:555-581, May.

Murcia, A. (2007 ). "Determinantes del acceso al crédito de los hogares colombianos", Ensayos sobre Política Económica, n. ${ }^{\circ}$ 55, Banco de la República.

Newman, M.E.J. (2003). "The Structure and Function of Complex Networks", SIAM Review, vol. 45, n. $^{\circ} 2$.

Newman, M.E.J. (2010). Networks, Oxford University Press.

Norman, B.; Brierley, P.; Gibbard, P.; Mason, A.; Meldrum, A. (2009).“A risk-based methodology for payment systems oversight", Journal of Payments Strategy \& Systems, vol. 3, n. ${ }^{\circ}$, August. 
Ötker-Robe, I.; Narain, A.; Ilyina, A.; Surti, J., (2011). “The Too-important-to-fail conundrum: impossible to ignore and difficult to resolve", IMF Staff Discussion Note, n. ${ }^{\circ}$ 11/12, International Monetary Fund, May.

Rebonato, R. (2007). Plight of the Fortune Tellers, Princeton University Press.

Rodríguez-Moreno, M. and Peña, J.I. (2011). "Systemic risk measures: the simpler the better?", BIS Papers, n. ${ }^{\circ}$ 60, July 28.

Saunders, A.; Smith, R.C.; Walter, I. (2009). "Enhanced Regulation of Large, Complex Financial Institutions", Restoring Financial Stability (Eds. Acharya, V.V. and Richardson, M.), Wiley Finance.

Soramäki, K.; Bech, M.; Arnold, J.; Glass, R.; Beyeler, W. (2006). “The topology of interbank payments flow", Federal Reserve Bank of New York Staff Report, n. ${ }^{\circ} 243$, March.

Steiner, J. (2006 ). "World University Rankings - A Principal Component Analysis”, Instituto de Estúdios Avançados da Universidade de São Pablo.

Taleb, N.N. (2007). The Black Swan, Random House.

Tucker, P., "Where are the Risks?" (2005). Financial Stability Review, Bank of England, December.

Tumpel-Gugerell, G. (2009). Introductory remarks, Recent advances in modeling systemic risk using network analysis (workshop), European Central Bank, Frankfurt am Main, October $5^{\text {th }}$.

Tunstel, E.; Seraji, H.; Howard,A. (2001). "Soft Computing Approach to Safe Navigation of Autonomous Planetary Rovers", Intelligent Control Systems Using Soft Computing Methodologies (Eds. Zilouchian, A. and Jamshidi, M.), CRC Press.

Uribe, J.D. (2011a). "Casting Light on Shadow Banking: Data Needs for Financial Stability”, Speech delivered at the IMF Statistics Department Seminar (Washington D.C.), September 23.

Uribe, J.D. (2011b). "Lessons from the 2008 Financial Crisis: How Financial Infrastructures Mitigate Systemic Fragility", Speech delivered at the Seacen-Cemla Conference, (Kuala Lumpur, Malaysia), October 13. 
Zhou, C. (2009). Are banks too big to fail? Measuring systemic importance of financial institutions, De Nederlandsche Bank.

\section{Exhibit A: Assessing connectedness and substitutability with network analysis basics}

As explained throughout the document, literature recognizes three criteria as key to measuring and identifying systemic importance: size, connectedness and substitutability (IMF et al., 2009; Manning et al., 2009). Because of their novelty and intricacy, the first two sections of this exhibit briefly describe the methodologies imported from network analysis in order to measure connectedness and substitutability $^{19}$, where the third section displays some results obtained with the described methodologies.

In order to make this exhibit comprehensible it is worth acknowledging the following concepts (Table A1), which pertain to network analysis terminology.

Table A1. Network analysis basic terminology

\begin{tabular}{|l|l|}
\hline \multicolumn{1}{|c|}{ Term } & \multicolumn{1}{c|}{ Description } \\
\hline Vertex & The fundamental unit of a network. Also referred to as node, actor or participant. \\
\hline Edge & $\begin{array}{l}\text { The line connecting two vertices. Also referred to as bond, link or tie. It may be directed } \\
\text { if it runs in only one direction or undirected if it runs in both directions. }\end{array}$ \\
\hline Degree & $\begin{array}{l}\text { The number of edges connected to a vertex. In-degree (out-degree) refers to the number } \\
\text { of incoming (outgoing) edges. }\end{array}$ \\
\hline Geodesic path & $\begin{array}{l}\text { It is the shortest path through the network from one vertex to another. Note that there may } \\
\text { be more than one geodesic path between two vertices, and that in a directed network the } \\
\text { geodesic path may be different from one vertex to another and its reverse. }\end{array}$ \\
\hline Distance & $\begin{array}{l}\text { The number of links that is minimally needed to connect two vertices. Neighbors (di- } \\
\text { rectly connected) have distance equal to 1; neighbors of neighbors that are not directly } \\
\text { connected are at distance 2, and so forth. }\end{array}$ \\
\hline
\end{tabular}

Source: authors' design, based on Buechel and Buskens (2008) and Newman (2003).

In Figure A1 the previous concepts could be applied as follows: the graph consists of seven vertices or nodes (i.e. A, B, C, D, E, F, G), where the A node is

19 Network analysis provides many other metrics and measures related to centrality. This exhibit focuses on the approach chosen by the authors. For a comprehensive review and explanation of alternative metrics and measures refer to Newman (2010).

PP. $125-165 \cdot N .{ }^{\circ} 7 / 2012-2013$ 
connected to nodes $\mathrm{E}$ and $\mathrm{D}$ via two undirected edges ${ }^{20}$ (i.e. incoming/outgoing from/to E and D); thus, the in-degree and out-degree of $\mathrm{A}$ is two. There are two geodesic paths from nodes A to G, consisting of three edges (i.e. the path A-D-F$\mathrm{G}$ and the path A-E-F-G).

Figure A1. A simple undirected network

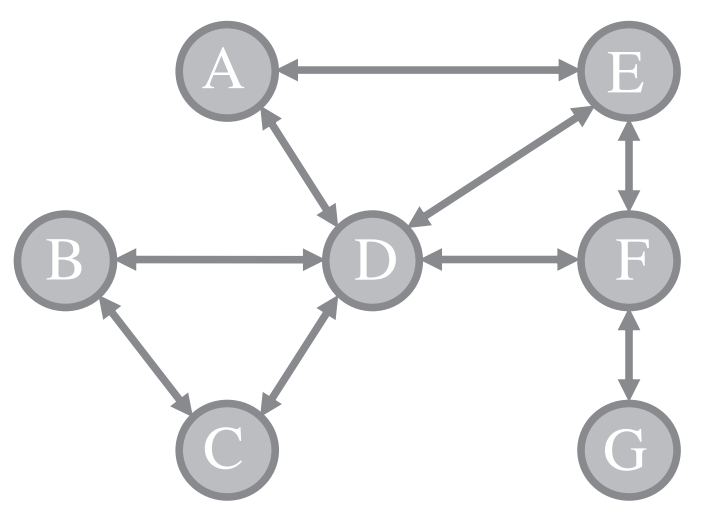

Source: authors' design

\subsection{Connectedness}

The main intuition of the connectedness criteria asserts that the larger the number -and volume- of the links an institution maintains with other market participants, the larger the contagion or spillovers it may generate; this is, the systemic importance of a financial institution generally increases with its degree of connectedness.

According to Newman (2010) and de Nooy et al. (2005), the simplest centrality measure in a network is the degree of a vertex; this is, the number of edges connected to it, or the number of its neighbors. This type of centrality metric assesses how intensely the vertex is connected to the network, which relates in our case to how easily can payments arrive to or spread from that vertex. For example, in Figure A1 the most central vertex (i.e. with most edges) is D, which has five of them.

It is common to find that the degree of each vertex is normalized with respect to the highest degree attainable. Let $N$ be the number of vertices in a network,

\footnotetext{
20 Because network analysis is to be applied to payments, where each payment is necessarily related to an immediate, previous or forthcoming transfer of a financial asset (e.g. a bond, a stock, money, etc.), note that directed edges (i.e. with only one direction) will not be considered.
} 
and $E_{D}$ the degree of vertex $\mathrm{D}$, then $(N-1)$ is the highest degree attainable, then the degree centrality of vertex $\mathrm{D}\left(C_{D}\right)$ may be expressed as in (4). Note that if a vertex is connected to all the other vertices of the network its degree centrality will equal 1, whilst an isolated vertex (not connected to the network) will yield a degree centrality equal to 0 .

$$
C_{D}=\frac{E_{D}}{N-1}
$$

Therefore, because of its documented simplicity and usefulness, the authors rely on degree centrality as a customary metric for connectedness. Nevertheless, degree centrality of a vertex or node would suffice to assess its centrality only if all edges are judged as equally important; this is the standard case of network analysis applied to social relations or informational networks. In the case in hand, where edges represent payments, it is convenient to recognize the importance of each edge according to the value of the payments it intends to represent.

Consequently, as in other applications of network analysis ${ }^{21}$, it is important to consider each edge's strength, weight or value. Let Figure A 2 be a weighted version of Figure A1, where each edge's number represents the weight of the connection between the vertices. It is rather evident that vertex D remains as the most important regarding the weight of the edges it shares with other vertices, with weights adding up to 13 .

Figure A2. A weighted network

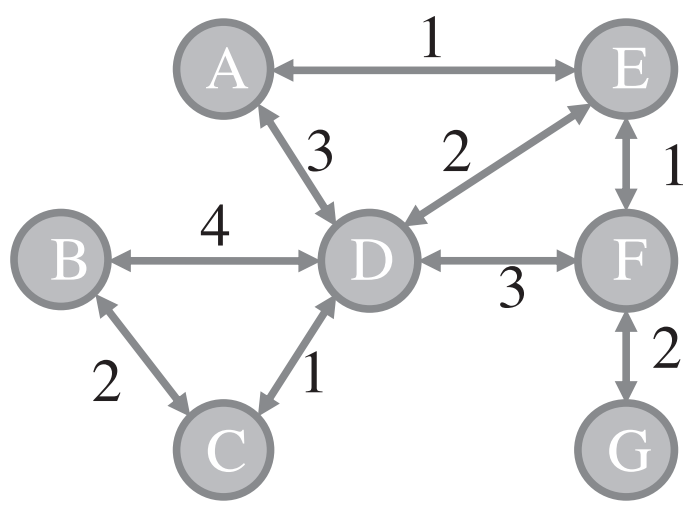

Source: authors' design

21 A common case of weighted networks is the bandwidth or the amount of data flowing between nodes within the world wide web (Newman, 2010). 
Considering the edges' weights provides new information that was not apparent when using degree centrality. Vertices B and C in Figure A1 appear to be equally central, both with two undirected edges, both sharing connections between themselves and to vertex D; moreover, when calculating the degree centrality as in (4), $\mathrm{B}$ and $\mathrm{C}$ yield the same result $\left(E_{B} /(N-1)=E_{C} /(N-1)=2 / 6=0.33\right)$. Despite sharing the same degree centrality, it is rather clear in Figure B2 that considering weights would signal vertex $\mathrm{B}$ as being more intensely connected than vertex $\mathrm{C}$, with weights equal to 6 and 3, respectively.

Analogous to degree centrality, the authors normalize the total weight of each vertex with respect to the sum of each vertex's edge weight. ${ }^{22}$ Let $W_{j}$ represent the total weigh of all the edges of vertex $j$, each vertex's share of the network's weight $\left(V_{j}\right)$ may be expressed as in (5).

$$
V_{j}=\frac{W_{j}}{\sum_{j=1}^{N} W_{j}}
$$

Vertex D, which displays the most weight, yields a 0.342 share of the network's weight. Calculating B's and C's share of the network's weight would yield 0.158 and 0.079 , respectively, avoiding considering $\mathrm{B}$ and $\mathrm{C}$ as equally important within the network because of exhibiting the same number of edges. Unfortunately, comparing B's and F's share of the network's weight (both 0.158) would consider these two vertices as equally important to the network despite $\mathrm{F}$ has one more neighbor than B.

Because both approaches to assessing the intensity of the connection are valuable for the case in hand (i.e. payments), where the systemic importance increases with the number of connected institutions and with the share of the total payments, the authors use the product ${ }^{23}$ of both metrics as an overall measure of the contribution to the payment system $\left(K_{j}\right)$, as in (6):

22 Note that the calculation of $V_{j}$ as in (5) counts the weights separately in either direction between each vertex pair, which results in counting each weigh twice. As pointed out by Newman (2010), it is possible to compensate for this double-counting by dividing each weight by 2 ; nevertheless it makes little difference since the analysis focuses on the relative magnitudes and not the absolute values. Moreover, this notation allows for applying (5) to directed networks as well.

23 Note that multiplying both metrics (i.e. the degree centrality and the share of the network's total weight) is analogous to using the AND -conjunction- operator in Fuzzy Logic (Cox, 1994). 


$$
K_{j}=C_{j} \times V_{j}
$$

Based on Figure A2, the result of employing such approach is presented in Table A2, where $K_{j}$ corresponds to the $j$-vertex overall contribution to the network, and Kindex $x_{j}$ corresponds to the standardized value of $K_{j}$ in a 0 to 10 scale. ${ }^{24}$

It is worth noticing that (i) the vertex most contributing to the network is D, receiving the highest score in the 0 to 10 scale, which is intuitive since is the vertex with most connections and with the highest share of the network's weight; (ii) the vertex less contributing to the network is $\mathrm{G}$, receiving the lowest score; (iii) vertices $\mathrm{B}$ and $\mathrm{C}$ are no longer deemed as equally important as with degree centrality alone, where $\mathrm{B}$ is more important than $\mathrm{C}$ because of the latter's edges weights; and (iv) vertices $\mathrm{B}$ and $\mathrm{F}$ are no longer deemed as equally important as with the share to the network's total weight, where $\mathrm{F}$ is more important than $\mathrm{B}$ because of the former's number of edges . Hence, as displayed in Table A2, using the product of both metrics allows for comprehensively and intuitively assessing the importance of the network's vertices.

Table A2. Contribution to the network

\begin{tabular}{|c|c|c|c|c|}
\hline Vertex & $\boldsymbol{C}_{\boldsymbol{j}}$ & $\boldsymbol{V}_{\boldsymbol{j}}$ & $\boldsymbol{K}_{\boldsymbol{j}}$ & Kindex $_{\boldsymbol{j}}$ \\
\hline $\mathrm{A}$ & 0,3333 & 0,1053 & 0,0351 & 1,2 \\
\hline $\mathrm{B}$ & 0,3333 & 0,1579 & 0,0526 & 1,8 \\
\hline $\mathrm{C}$ & 0,3333 & 0,0789 & 0,0263 & 0,9 \\
\hline $\mathrm{D}$ & 0,8333 & 0,3421 & 0,2851 & 10,0 \\
\hline $\mathrm{E}$ & 0,5000 & 0,1053 & 0,0526 & 1,8 \\
\hline $\mathrm{F}$ & 0,5000 & 0,1579 & 0,0789 & 2,8 \\
\hline $\mathrm{G}$ & 0,1667 & 0,0526 & 0,0088 & 0,3 \\
\hline
\end{tabular}

Source: authors' calculations

If a vertex displays both a high (low) level of centrality AND a high (low) level of contribution to the network's total weight, then the product of both levels will be high (low).

24 As previously introduced (footnote 14), this standardization procedure assigns the maximum index value (10) to the most contributing vertex, and the rest is assigned an index value by means of linear interpolation. Such standardization is straightforward and makes comparisons and calculations easier. 


\subsection{Substitutability}

The severity of the impact of a payment system failure, and hence the extent of systemic risk, depends critically on whether substitutes are readily available to allow payment flows to be rerouted via another system (Manning et al. 2009). Consequently, the systemic importance of a financial institution generally decreases with its degree of substitutability.

A key concept for assessing substitutability comes from network analysis' betweenness centrality. Betweenness centrality measures the brokerage role of a certain vertex within a network (Buechel and Buskens, 2008) or, as defined by de Nooy et al. (2005), it captures the extent to which a vertex is needed as a link in the chain of contacts that facilitate the spread of information within a network; the more a vertex is a go-between, the more central its position in the network.

The calculation of betweenness centrality relies on the geodesic path concept, which is the shortest path through the network from one vertex to another. It is calculated for vertex $j$ as the proportion of all geodesic paths between pairs of other vertices that include such vertex (de Nooy et al., 2005). Let $G_{p q}$ be the number of geodesic paths between vertices $p$ and $q$, and $G_{p q}^{j}$ the number of geodesic paths between $p$ and $q$ that go through vertex $j$, betweenness centrality of vertex $j\left(B_{j}\right)$ is calculated as in (7):

$$
B_{j}=\Sigma_{p q} \frac{G_{p q}^{j}}{G_{p q}}, \forall G_{p q} \neq 0, p \neq j, q \neq j, p \neq q
$$

Nevertheless, because substitutability is related to the severity of the impact of a vertex being removed, which depends on whether substitutes are readily available to allow preserving the distances between vertices, betweenness centrality by itself fails to address this criteria in a proper manner. Betweenness centrality captures the importance of a vertex as an intermediary between all the others vertices that compose the network, but it does not capture the severity of the impact resulting from the removal of a vertex.

Because substitutability relates to the severity of the impact for the geodesic path between vertices $p$ and $q\left(G_{p q}\right)$ resulting from the removal of a $j$-vertex, which could be conveniently defined in terms of distance between the remaining vertices, consider that there are three possible scenarios resulting from removing $j$ from the network: (i) there is no change in the distance corresponding to the geodesic path 
between vertices $p$ and $q\left(G_{p q}\right)$ because other vertex or vertices could substitute the removed $j$-vertex, or because the $j$-vertex does not pertain to the geodesic path $\left(G_{p q}\right)$; (ii) other vertex or vertices could substitute the removed $j$-vertex, but with an increase in the distance corresponding to the new geodesic path between vertices $p$ and $q\left(G_{p q}\right)$; and (iii) there is no other vertex or vertices which may serve the purpose of indirectly connecting vertices $p$ and $q$, hence there would be no geodesic path between them $\left(G_{p q}=0\right)$, and the distance between vertices $p$ and $q$ would be defined as a number larger than any other possible distance in the network. ${ }^{25}$

These three scenarios are depicted in Figure A3. The vertex removed changes in each panel of the figure, and the geodesic path to be analyzed is the one corresponding to connecting vertices $\mathrm{C}$ and $\mathrm{H}$ :

Figure A3

Scenarios of substitutability

Geodesic path connecting vertices $\mathrm{C}$ and $\mathrm{H}$

Scenario (i)

Removal of $\mathrm{A}$

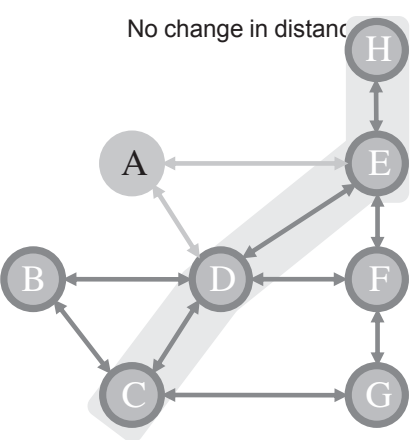

Source: authors' design
Scenario (ii)

Removal of $D$

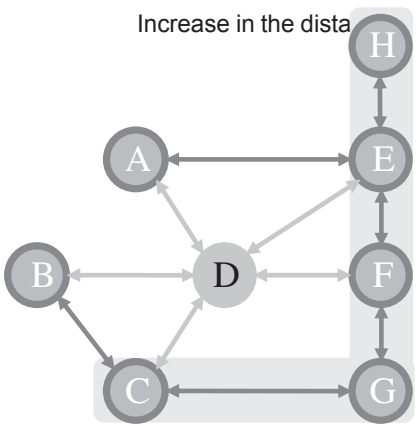

Scenario (iii)

Removal of $\mathrm{E}$

Disconnection

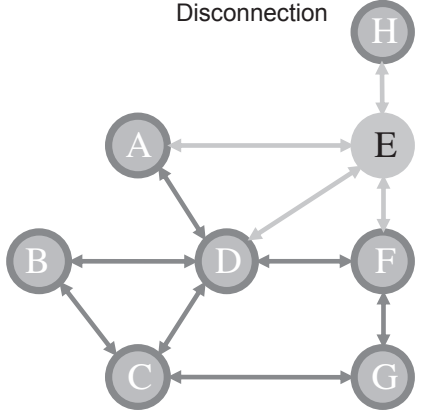

In Scenario (i) the impact resulting from the removal of vertex A is nil; the geodesic path between $\mathrm{C}$ and $\mathrm{H}\left(G_{C H}\right)$ comprises two vertices (D and $\mathrm{E}$, with a total distance of 3), where vertex A is not present. In Scenario (ii) the impact from the removal of vertex $\mathrm{D}$ is an increase in the distance between $\mathrm{C}$ an $\mathrm{H}$, which increases from 3 to 4 where vertices G, F and E belong to this new geodesic path. Scenario (iii)

25 Buechel and Buskens (2008) suggest assigning a number larger than any possible actual distance in the network for those pairs of vertices that cannot reach each other, and choose to use $N$; this is also the authors' choice. 
exhibits the third case, where the removal of vertex E results in the impossibility of connecting vertices $\mathrm{C}$ and $\mathrm{H}$.

Consequently, for the relation between vertices $\mathrm{C}$ and $\mathrm{H}$, vertex $\mathrm{E}$ is not substitutable (i.e. no other vertex or vertices are able to fulfill its role), vertex A is not relevant (i.e. the geodesic path does not includes vertex A), and vertex D is substitutable but with an increase in the distance between $\mathrm{C}$ and $\mathrm{H}$. This result is relevant and emphasizes the importance of considering both connectedness and substitutability: degree centrality alone would consider Figure A3's vertex E as of lower systemic importance than D (i.e. E has less edges than D), and would not recognize that the removal of $\mathrm{D}$ does not result in a major disruption in the network (i.e. it would be substituted by using other-longer- paths), whilst the removal of $\mathrm{E}$ would result in a vertex being disconnected from the network.

Accordingly, the approach chosen by the authors to assess the substitutability of each vertex comprising the network consists of an iterative procedure of the analysis just described. This is, (i) calculating the average distance of the geodesic paths for all the vertices within the network; (ii) removing a vertex from the network and recalculating the average distance of the geodesic paths for all the vertices within the network; (iii) calculating the increase in the average distance of all the geodesic paths after removing the vertex; (iv) repeating these steps for all the network's vertices.

This procedure will yield each vertex's effect on the average distance of the geodesic paths of the network, which is a distance-based metric for assessing the severity of the impact of a vertex being removed, and a useful metric for substitutability. It is expected that (i) removing a perfectly substitutable vertex (i.e. may be substituted without increasing the distance of the geodesic paths) will result in a constant average distance of the geodesic paths for all vertices within the network; (ii) removing a non-perfectly substitutable vertex will result in an increase in the average distance of the geodesic paths, whereas the magnitude of the increase is negatively related to the substitutability of the vertex; and (iii) removing a nonsubstitutable vertex will result in an increase in the average distance of the geodesic paths and the disconnection of one or more vertices of the network.

\section{Exhibit B: Principal Components Scoring Factors}

In this appendix the values of the first principal components of four systemic characteristics of financial institutions are reported. In addition, the corresponding 
value of the explained variance by each of the principal components is represented by the value of $\lambda$, whereas this information is calculated for the three dates considered in the document.

Figure B1

Scoring Factors

(May, June, July, 2011)

\begin{tabular}{|c|c|c|c|c|}
\hline May 2011 & PC1 & PC2 & PC3 & PC4 \\
\hline A & 0,56 & $-0,11$ & $-0,61$ & $-0,55$ \\
\hline B & 0,17 & 0,98 & $-0,02$ & 0,00 \\
\hline $\mathrm{C}$ & 0,77 & $-0,12$ & 0,62 & 0,13 \\
\hline $\mathrm{D}$ & 0,26 & $-0,06$ & $-0,50$ & 0,82 \\
\hline$\lambda$ & $59,2 \%$ & $25,6 \%$ & $10,2 \%$ & $5,0 \%$ \\
\hline June 2011 & PC1 & PC2 & PC3 & PC4 \\
\hline A & 0,52 & $-0,03$ & $-0,15$ & 0,84 \\
\hline B & 0,15 & 0,88 & 0,45 & 0,02 \\
\hline $\mathrm{C}$ & 0,63 & 0,20 & $-0,58$ & $-0,49$ \\
\hline $\mathrm{D}$ & 0,56 & $-0,43$ & 0,66 & $-0,24$ \\
\hline$\lambda$ & $56,5 \%$ & $21,1 \%$ & $18,5 \%$ & $3,9 \%$ \\
\hline July 2011 & PC1 & PC2 & PC3 & PC4 \\
\hline A & 0,65 & $-0,18$ & $-0,07$ & 0,74 \\
\hline B & 0,23 & 0,97 & 0,01 & 0,03 \\
\hline $\mathrm{C}$ & 0,72 & $-0,15$ & $-0,10$ & $-0,67$ \\
\hline $\mathrm{D}$ & 0,11 & $-0,04$ & 0,99 & $-0,01$ \\
\hline$\lambda$ & $50,2 \%$ & $24,9 \%$ & $19,8 \%$ & $5,2 \%$ \\
\hline \multicolumn{5}{|c|}{ Source: authors' calculations } \\
\hline
\end{tabular}

It is worth mentioning that the first principal component explains more than the $50 \%$ of the variance for the three dates, and that the four first principal components together (PC1, PC2, PC3 and PC4) explain 100\% of the variance of the sample. 
The importance of a systemic characteristic such as the volume of financial assets under management (factor B) is increased if the second principal component is considered; in this component that characteristic presents a high and positive scoring factor. In the hypothetic case in which the first principal component would explain a low proportion of the sample variance, the combination of two or more principal components should be used. In that case the characteristic of size represented by the volume of financial assets under management would probably gain more importance into the systemic index. As in the considered observations this is not the case, it is safe to use the first component as an instrument to obtain an appropriate weight of this kind of characteristics. 